\title{
Developing a Prosthesis Design using A Gearbox to Replicate the Human Hand Mechanism
}

\author{
Haneen Mahdi Jaber* Muhammed Abdul-Sattar** \\ Nabel Kadhim Abd al-Sahib*** \\ *,**Department of Mechanical Engineering /College of Engineering/Al-Nahrain University \\ ***Department of Medical Engineering /College of Engineering/Al-Nahrain University \\ *Email: hanen990990@gmail.com \\ **Email:m1976sjnr@gmail.com \\ ***Email: n-k-alsahib@Yahoo.com
}

(Received 26 January 2020; accepted 26 April 2020)

https://doi.org/10.22153/kej.2020.04.001

\begin{abstract}
Prosthetic is an artificial tool that replaces a member of the human frame that is absent because of ailment, damage, or distortion. The current research activities in Iraq draw interest to the upper limb discipline because of the growth in the number of amputees. Thus, it becomes necessary to increase researches in this subject to help in reducing the struggling patients. This paper describes the design and development of a prosthesis for people able and wear them from persons who have amputation in the hands. This design is composed of a hand with five fingers moving by means of a gearbox ism mechanism. The design of this artificial hand has 5 degrees of freedom. This artificial hand works based on the principle of under actuated system. The used motor is 6V Polulu high-power carbon brush micro metal gearmotor with gear ratio equal to 50:1. The motor was chosen due to its compactness and cheapness. The hand manufacturing process was done using a 3D printer and using polylactic acid material. Numbers of experiments were accomplished using the designed hand for gripping objects. Initially, the electromyography signal (EMG) was recorded when the muscle contracted in one second, two seconds, three seconds. The synthetic hand was able to produce a range of gestures and grasping for objects.
\end{abstract}

Keywords: Prosthesis, gearbox mechanism, pololu high, Solid work, 3D printing.

\section{Introduction}

The personal hand is an integration of complicated systems of tendons, stress, muscles, and frame. Behind a hand border, the capability of people to investigate and react to their ambiance. An unfortunate feature a compact manual ability, having difficulty with controlling and detecting objects. Physical variations, among others, will result in psychological problems [1]. The human hand has 22 degrees of freedom [2], which are created by 27 unique bones and 30 muscles [3]. Nearly thirty-five percent of the removed appendages are removed of arm or portion of the arm. Until a long time back, the advancement of prosthetic hand that brings back the capacities and steadfastness. For individuals who have removal, the arrangement and improvement of any prosthesis depend on many-sided quality of the body portion being supplanted and rehabilitative necessities of the prosthesis client. Upper appendage prostheses are set for those people who have either portion or entirety upper appendage nonattendance, which may either be obtained (through removal) or innate the prosthetic hand is as it were portion that can imitate the 
developments and capacities of the human hand in the day by day work. C. Pylatiuk, explain a new experimental hand restorative design that differs from the typical prostheses. With the idea of addressing consumers' necessities, practicality was increased, and the cosmetic look became close to the lost body part [4]. T.Maeno developed a five-fingered hand having around a break even with several degrees of freedom toward the person's hand. The machine hand is decided in an interesting way utilizing ultrasonic engines and flexible parts [5]. E.Tumas.Wiste developed a new design to acquire a complete grasping taxonomy. It composed of eight required hand postures with the possibility of controlling them by EMG signals. The design consisted of an thropomorphic hand having five fingers with 16 joints [6]. Rocha, made several studies deal with the applied forces by the hand throughout the griped objects in process [7]. T.Joseph.MS.BS.Belter, studied the mechanical properties of the artificial industrial hands has been performed. A pilot study on the impact of many commercially available reproductive health labor, including Vincent, iLimb, iLimb Pulse, Bebionic, Bebionic v2, and Michelangelo hands were reported. The design of the fingers and motility, the joint mechanical couple, and the operating methods of these artificial hands were commercially invested [8]. G.K.Jones studied the stability of the mechanical design of the primary hand mechanism. Also, it has appeared how the traditional circuit board fits within the palm, and a general idea of the modified manage framework is depicted, with potential future increases of amputee advice [9]. Abd Al-Sahib N. Kadhim and Muhammad A.M., presented a methodology to design and manufacture an artificial hand for prosthetic application. The proposed design is a five-finger hand with the forearm actuated by an under-actuated system composed of tendons and servomotors. The manufacturing strategy started by design the model using the Solidworks software and manufactured using the 3D printing technique. It possesses $15 \mathrm{DOF}, 3 \mathrm{DOF}$ for each finger [10]. This paper study the kinematic motion and the method of design of a prosthesis with a gearbox mechanism with full function of movement. Manufacturing of each part in the prosthetic hand and assembly it and then testing the hand for handling the objects were then conducted. The novelty of this paper include using the gearbox for the operating system and the mobility of the fingers, also includes the location of the DC motor in the palm of the hand.

\section{Methodology 2.1. Geometry Design}

This part explains the geometry design procedure used to design the mechanical function of the prosthetic hand. The design of the prosthetic hand is drawn using Solidworks, since Solidworks is introduced, it has been a great tool for every engineer who is interested in design. It is a complete computer-aided design (CAD) package that offers modeling of complicated structure. The first part to design was the finger, which consists of two parts: the distal phalange and the proximal phalange. The link between wheel gear and phalanges(proximal and distal) was done by using a worm wheel; when $6 \mathrm{~V}$ pololu motor is powered, the distal move up and linked with proximal phalange. The thumb is designed to do different functions from any other designed parts, and it is driven by two $6 \mathrm{~V}$ polou motor, and it is capable for extension and flexion. The palm is divided into two regions; one supports each finger, and the location of motors is called (back palm). The second part of the palm is called (upper palm). These parts work in a similar manner to the human hand, as shown in Figure (1). The forearm part is designed as a base to support the palm and the rest of amputation. The wrist is fixed and designed to join the forearm with palm.. All the designed parts are then assembled together in the Solidworks environment to form the final shape of prosthetic hand,see the figuresbelow.

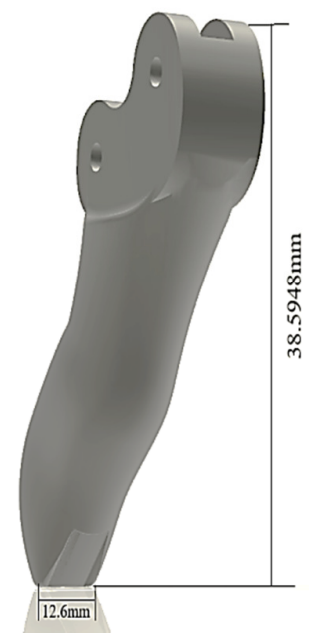

Fig. 1. Distal finger.

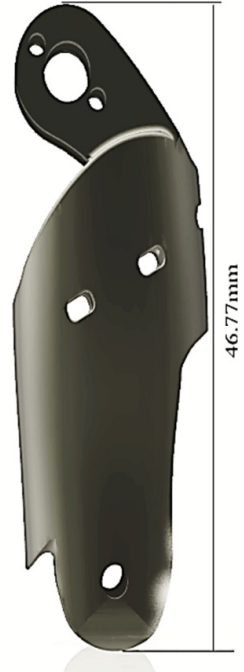

Fig. 2. Proximal finger. 

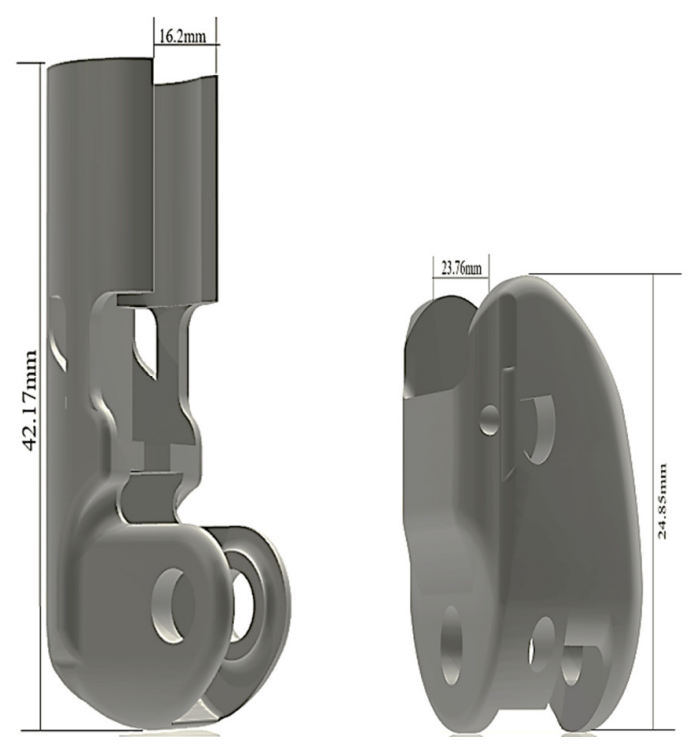

Fig. 3. Thumb motor design. Fig. 4.Thumb mount.

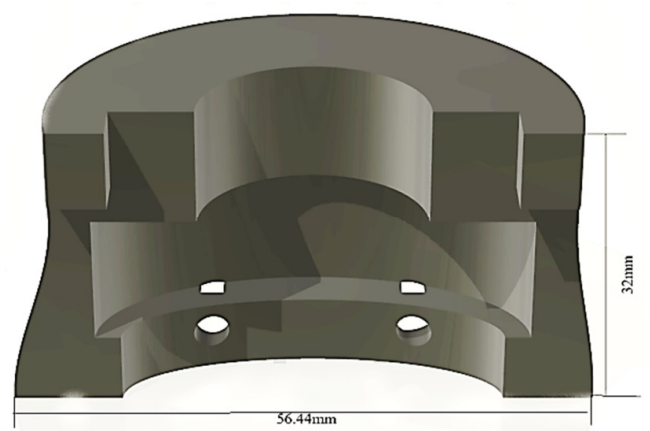

Fig. 5. Wrist design.

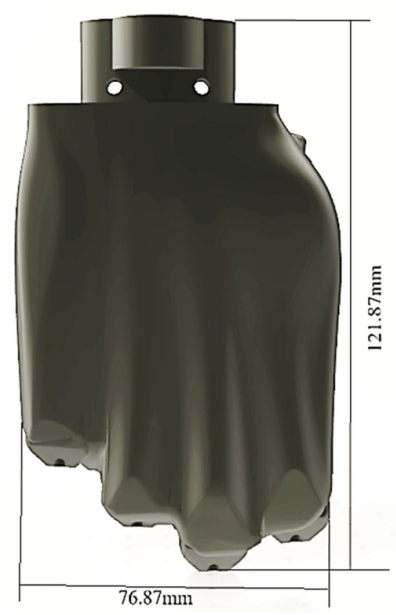

Fig. 6. Palm bottom design.

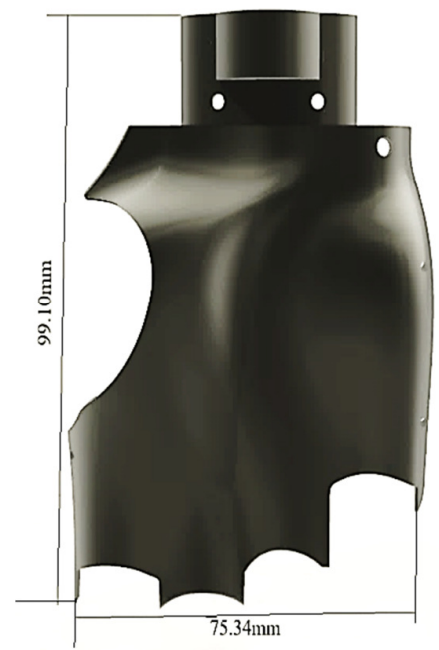

Fig. 7. Palm up rigid design.

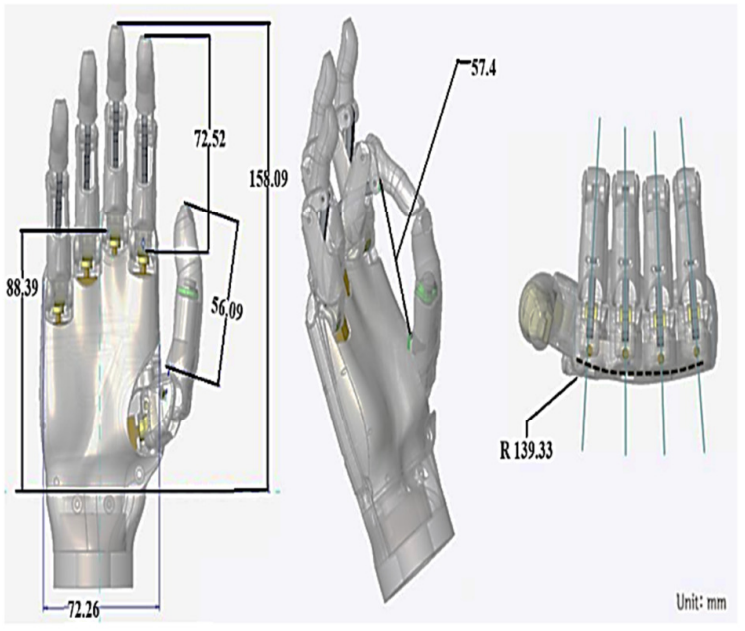

Fig. 8. Complete prosthetic hand design.

\subsection{Finger Kinematics}

In our kinematics model, the prosthetic finger comprises two connections relating to the two phalanges of the genuine finger. The finger is set with one active DOF and one passive. The active DOF is at the primary joint, and the other one is in the two joints combined with the first one. Denavit-Hartenberg (D-H) is generally utilized technique to take care of the forward kinematics issue, where the change in the arrangement is utilized to create an individual change demonstrating the heading and position of the fingertip as for palm. The finger kinematics can be considered in 2D kinematics lying in the $\mathrm{X}-\mathrm{Y}$ plane. The D-H theorem contains four parameters, 
which are: angle $\theta \_i$, the link/phalanx offset $d \_i$, the link /phalanx length $\mathrm{L} \_\mathrm{i}$, and the link/phalanx twist $\alpha \_i$. These four factors are utilized to figure the position and orientation of the fingertip. It is worth mentioning that the four fingers have the same range of rotation of joints but they differ in the dimensions of the phalanges (only the max length $\mathrm{L}_{-} \mathrm{i}$ ). See the figures below for the parameter in the fingers.

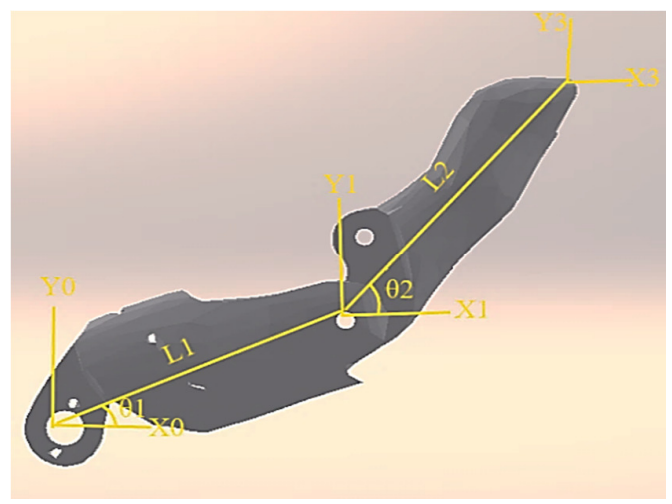

Fig. 9. Coordinate frames of finger.

Once the D-H outline framework has been set up for every link, a homogeneous transformation matrix will be without much of a stretch be produced recitation it coordinate casing the (i-1) coordinate casing [11]:

$T_{i}=\operatorname{Rot}_{z, \theta} \cdot \operatorname{Trans}_{z, d i} \cdot \operatorname{Trans}_{x, l i} \cdot \operatorname{Rot}_{x, \alpha i}$

The equation equal

$i-1_{T i}=$

$\left[\begin{array}{cccc}\cos \theta_{i} & -\sin \theta_{i} \cos \alpha_{i} & \sin \theta_{i} \cos \alpha_{i} & L_{i} \cos \theta_{i} \\ \sin \theta_{i} & \cos \theta_{i} & -\cos \theta_{i} \cos \alpha_{i} & L_{i} \sin \theta_{i} \\ 0 & \sin \alpha_{i} & \cos \alpha_{i} & d i \\ 0 & 0 & 0 & 1\end{array}\right]$ This equation

D-H parameters for the fingers are shown in Table (1),(2).

Table 1,

D-H parameter for the finger

\begin{tabular}{|c|c|c|c|c|}
\hline $\begin{array}{l}\text { Link } \\
\text { no. }\end{array}$ & $\begin{array}{l}\text { Length } \\
\mathbf{L i}\end{array}$ & $\begin{array}{l}\text { Twist } \\
\alpha \mathbf{i}\end{array}$ & $\begin{array}{l}\text { Offset } \\
\text { di }\end{array}$ & $\begin{array}{l}\text { Angle } \\
\theta i\end{array}$ \\
\hline 1 & L1 & 0 & 0 & $\theta 1$ \\
\hline 2 & L2 & 0 & 0 & $\theta 2$ \\
\hline
\end{tabular}

Table 2,

D-H parameter for the thumb

\begin{tabular}{lllll}
\hline $\begin{array}{l}\text { Link } \\
\text { no. }\end{array}$ & $\begin{array}{l}\text { Length } \\
\text { Li }\end{array}$ & $\begin{array}{l}\text { Twist } \\
\boldsymbol{\alpha i}\end{array}$ & $\begin{array}{l}\text { Offset } \\
\text { di }\end{array}$ & $\begin{array}{l}\text { Angle } \\
\mathbf{\theta i}\end{array}$ \\
\hline 1 & $\mathrm{~L} 1$ & $\pi / 2$ & 0 & $\theta 1$ \\
2 & $\mathrm{~L} 2$ & 0 & 0 & $\theta 2$ \\
\hline
\end{tabular}

Substituting the parameters in the above tables in Equation 2and referring to $\cos$ as (c) and for $\sin$ as (s)

${ }_{2}^{0} T={ }_{1}^{0} T{ }_{2}^{1} T=$

$\left[\begin{array}{cccc}c\left(\theta_{1}+\theta_{2}\right) & -s\left(\theta_{1}+\theta_{2}\right) & 0 & L_{1} c \theta_{1}+l_{2} c\left(\theta_{1}+\theta_{2}\right) \\ s\left(\theta_{1}+\theta_{2}\right) & c\left(\theta_{1}+\theta_{2}\right) & 0 & L_{1} s \theta_{1}+l_{2} s\left(\theta_{1}+\theta_{2}\right) \\ 0 & 0 & 1 & 0 \\ 0 & 0 & 0 & 1\end{array}\right]$

This equation

$[x i, y i, z i]=$ Orientation matrix of the it manage system traditional at connect I with deference to base coordinate edge. Upper left $2 * 2$ partitioned matrix of $\mathrm{T}$ i $\mathrm{i}$. Location of the vector pointing from origin of the base management system to the origin of the $p i=\mathrm{I}$ the coordinate system. Upper $2 * 1$ partitioned matrix of $\mathrm{T} \_\mathrm{i}$.

The solution for the position of the fingertip is found as given as :

$$
\begin{aligned}
& P_{x \text { fingertip }}=L_{1} \cos \theta 1+L_{2} \cos (\theta 1+\theta 2) \\
& P_{\text {ffingertip }}=L_{1} \sin \theta 1+L_{2} \sin (\theta 1+\theta 2) \\
& P_{\text {zfingertip }}=0 \\
& \emptyset=\theta 1+\theta 2
\end{aligned}
$$

\subsection{Prosthetic Hand Manufacture}

The prosthetic hand was built using 3D printing as an active additive manufacturing, which is a method utilized to fabricate almost any computer-aided design (CAD) model using thermoplastics materials, such as PLA, ABS, and PET. This method promises customization and simplicity with low-cost. The application of this method to fabricate parts suited to address local needs in developing countries has become of interest in recent years. The application of 3D printing in low-income countries, primarily using open-source designs, holds much promise for delivering a whole range of desired equipment on demand. The technology has been used to provide humanitarian aid to those in need [12].

Each finger of the prosthetic hand is actuated by $6 \mathrm{~V}$ polou motor with a gear ratio equal to $50: 1$ located at the palm. The proposed plan of the hand and the other parts of the hand were printed using the 3D printing technology. The printing procedure guarantees a high tall precision when it comes to dimension; i.e, there was not much contrast between the ultimate shape measurements and the CAD plan. As proposed, each finger is composed of two of these parts, which were connected together and fastened by pins between distal and proximal phalange. Figure (2) shows the finger in its final assembly. The palm on the 
other side is composed of two parts as planned. The fingers were attached to the palm in a simple, straightforward way; all parts are fitted together without noticeable clearance. Figure (3) shows the final shape of the designed prosthetic hand.

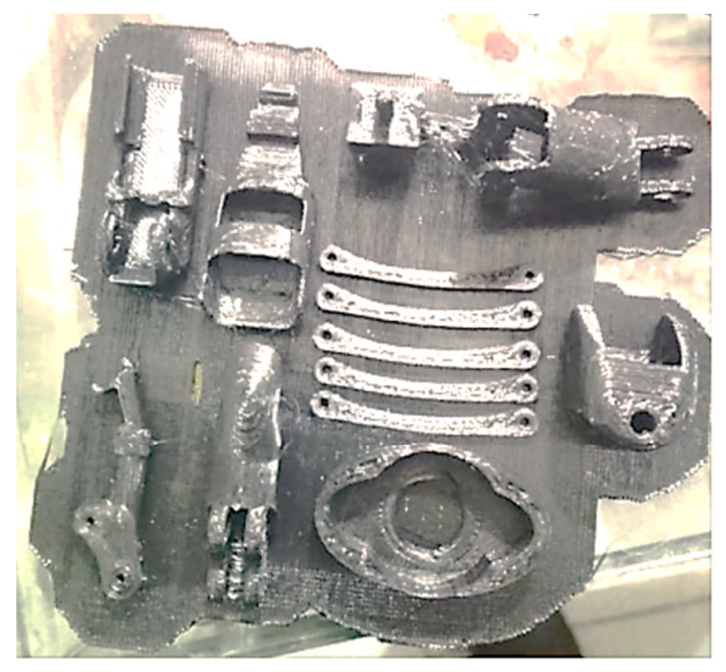

Fig. 10. Part of finger.

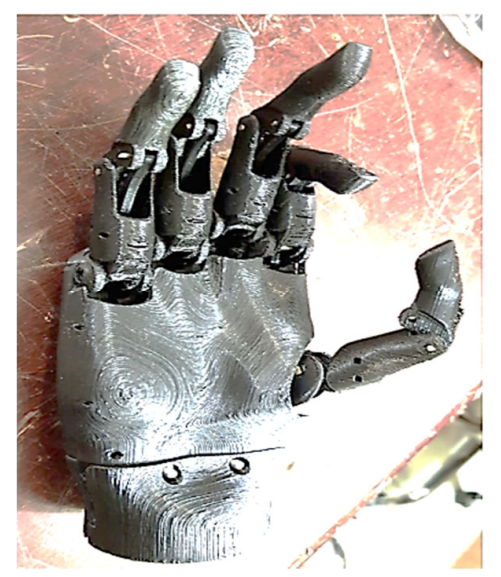

Fig. 11. Palm with finger.

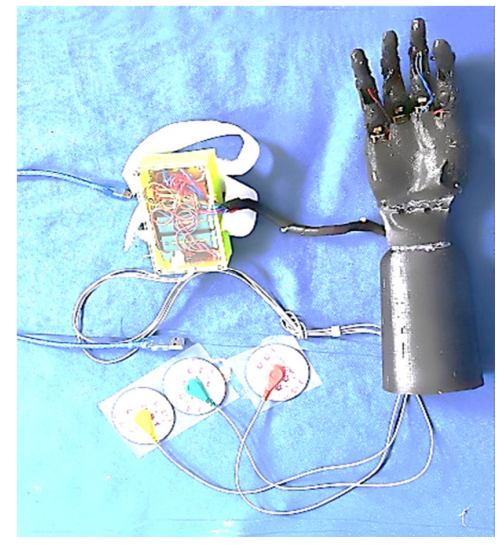

Fig. 12. Fully prosthetic hand.

\subsection{Driving Mechanism}

The gears system is composed of a worm that engaged with a gear wheel (the worm wheel), to produce the rotating motion will be moved between 2 beams at right angles to all other [13]. The worm-gear mechanism is illustrated in Figure (13), the motor is put closer to the metatarsophalangeal (MCP) joint but requires the motor axis to be offsetted. The worm gear is mounted on the motor shaft to drive the gear that is mounted on the proximal phalangeal. Turning the worm gear in one way or another will control the finger motion direction [14].

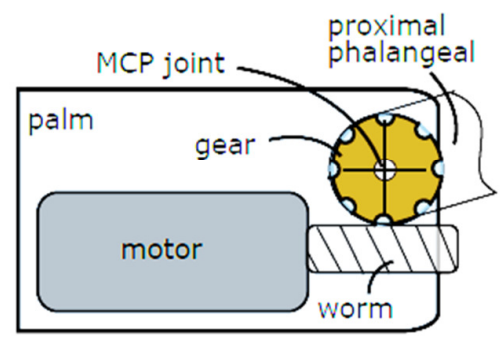

Fig. 13.Worm-gear finger mechanism .

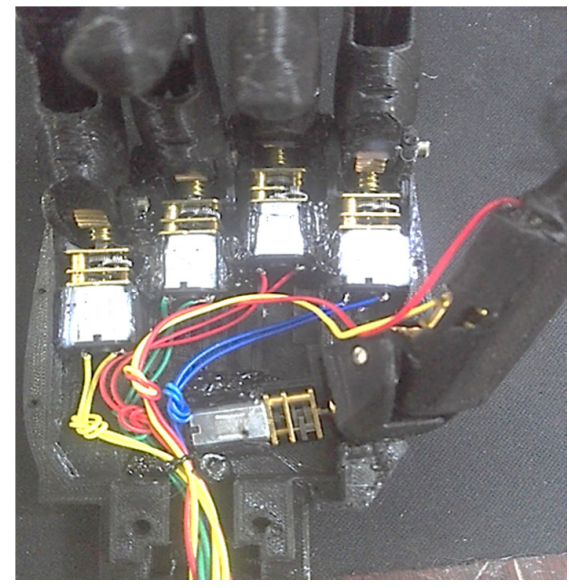

Fig. 14. Worm-gear with motor inside palm.

\subsection{Surface Electromyography Signal Generation (EMG)}

The EMG signal is defined as a recording and evaluating the electrical signal generated by the muscle that is related to neuromuscular activation. It emerges from the stream of ions across the muscle fibers' membrane, which passes through the connective tissues to arrive at the detection electrode, located on the skin [15]. The term EMG represent the Electromyography: The Electromyogram word contains three terms: 
electro, which implies touching on electrical activity; myo, that contains a Greek root that means muscle; and gram, that stands for recording. EMG is accomplished using an instrument called electromyography to make a record called electromyogram, that means the EMG is an electrodiagnostic procedure in the medical application for recording and evaluating the electrical activity created by skeletal muscles.

Figure (15) summarizes the composition of (EMG) signal. The signal that passes through muscle fibers coming through axon that induces muscle contraction or influences other neurons called action potential (AP). The motor unit action potential (MUAP) can be defined as the summation of electrical activity for all activated muscle fiber by an MU. In Figure (15) the $\alpha A$ and $\alpha \mathrm{B}$ are all alpha MUs recruited, the summation of muscle fibers APs that activated by $\alpha \mathrm{A}$ known as IMUAPA and the summation of muscle fibers APs that activated by $\alpha B$ known as $\Sigma$ MUAPB. This adds the MUAPs to each other in case of increasing the needed force, as a result of this summation of $\Sigma$ MUAPA and $\Sigma$ MUAPB the sEMG signal will emerge [16].

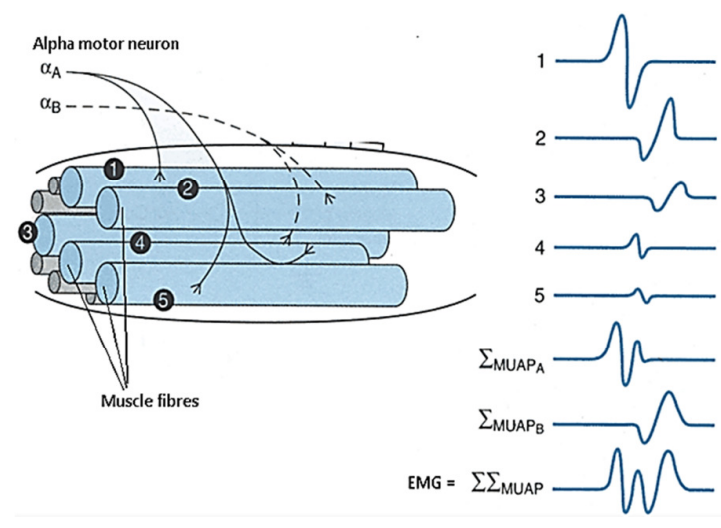

Fig. 15. EMG signal generation.

\section{Result and Discussion 3.1. Kinematics Motion}

The kinematics motion of the prosthetic hand means establishing the coordination of the fingertip with respect to the base frame and presenting the workspace and how the fingre will move. To describe the trajectory of motion of the finger tip statistical analysis for each point in the finger $(x, y$, and $z)$ is used. Figure (16) shows the 2D plot of the finger tip expressed in points for each part of the finger, and it represents the angle of the joint of the finger part to avoid overlapping.
The motion in $\mathrm{x}$, and $\mathrm{y}$ directions for the little finger was as $\mathrm{x}=0.968, \mathrm{y}=-1.63$, for the ring finger as $\mathrm{x}=0.692, \mathrm{y}=-1.643$, for the middle finger as $\mathrm{x}=0.964, \mathrm{y}=-2.09$, for the index finger as $\mathrm{x}=1.092, \mathrm{y}=-1.993$.

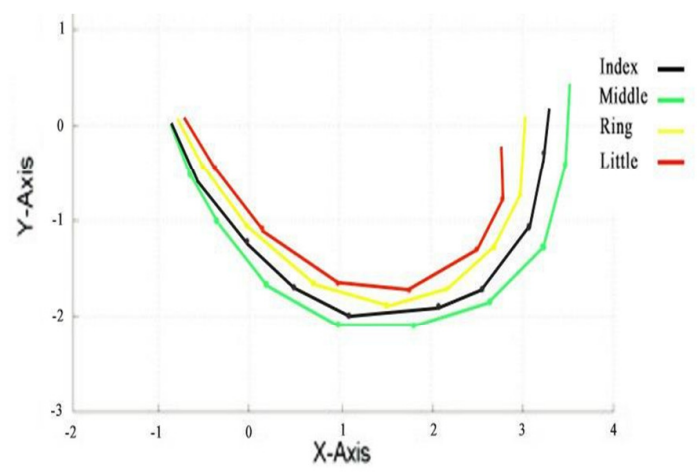

Fig. 16. 2D Fingertip Kinematic Motion.

In Figure (17) the blue line represents the thumb, which it intersects with the other lines (fingers). This intersection represents the validity of the prosthetic hand to grasp the objects. The thumb does not intersect with the little finger while the human thumb can intersect with the little finger. This intersection of the finger and overlapping with the thumb to the anthropomorphism of human hand and express the hand design is capable of movement and gripping object. This is an advantage in prosthetic hand designed.

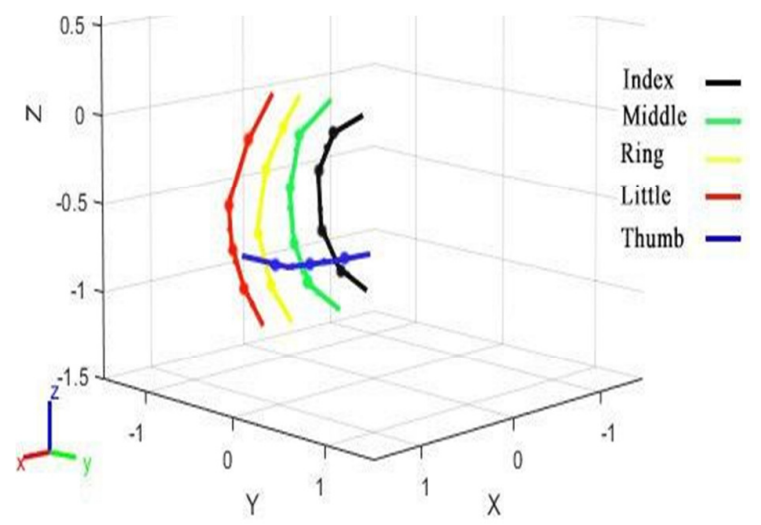

Fig. 17. 3D plot showing the intersection between thumb and finger.

\subsection{Prosthetic Hand Gripping Object}

After gathering the handle of prosthetic hand primary parts, the proposed hand design is tested . 
For the grasping design test, the hand is tested to hold three objects utilizing EMG as flag input. The prosthetic hand can effectively perform grasping the three objects. The three grasp designs are pinch, chuck, and fist. The prosthetic design was tested to gripping different objects, such as key, screwdriver, cart and cylindrical tray using EMG sensor with Arduino microcontroller and the signal generated from activities of muscles, see the Figures below.

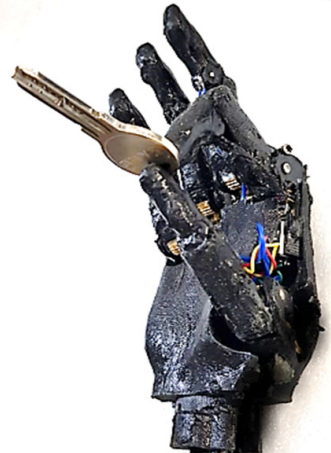

(A)

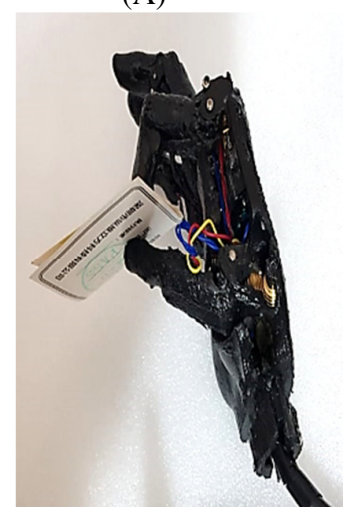

(C)

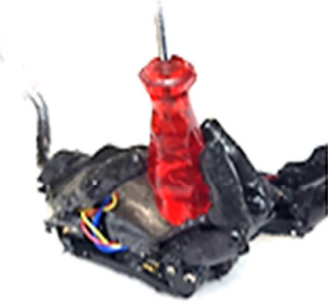

(B)

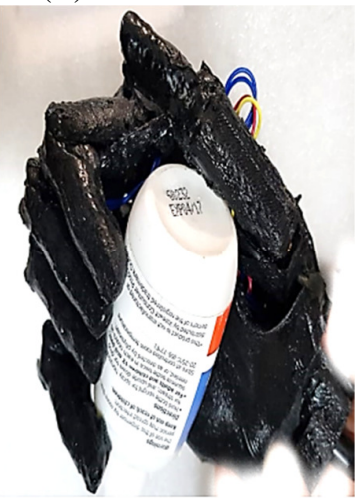

(D)

\subsection{The Pressure Effect}

The effect of the pressure applied by the hand on the objects has been studied from the pinch, chuck, and fist for the five fingers of the hands. For the pinch, the thumb and the index reaches the highest pressure with respect to the time, for the thumb it reaches $\left(960 \mathrm{~kg} / \mathrm{cm}^{2}\right)$ as for the index it reaches $\left(975.484 \mathrm{~kg} / \mathrm{cm}^{2}\right)$. As time increases, the pressure increases; after reaching a peak value, it starts to decrease. The effect on the thumb and index is the same at the chuck, enlarging the pressure into a peak value and the decreasing. For the fist, the pressure on th four fingers increases into a peak value with respect to the time and the decreases simultaneously, $\left(956.42 \mathrm{~kg} / \mathrm{cm}^{2}\right)$ for the index, $\left(942.285 \mathrm{~kg} / \mathrm{cm}^{2}\right)$ for the ring, $(876.564$ $\left.\mathrm{kg} / \mathrm{cm}^{2}\right)$ for the middle, $\left(875.725 \mathrm{~kg} / \mathrm{cm}^{2}\right)$ for the pinky.

Figure $(19,20,21)$ shows the effect of the pressure with respect to the time for the pinch, chuck, and fist, respectively.

Fig. 18. Prosthetic hand gripping (A) key,(B)s crew driver, (C) card and (D) cylindrical tray.

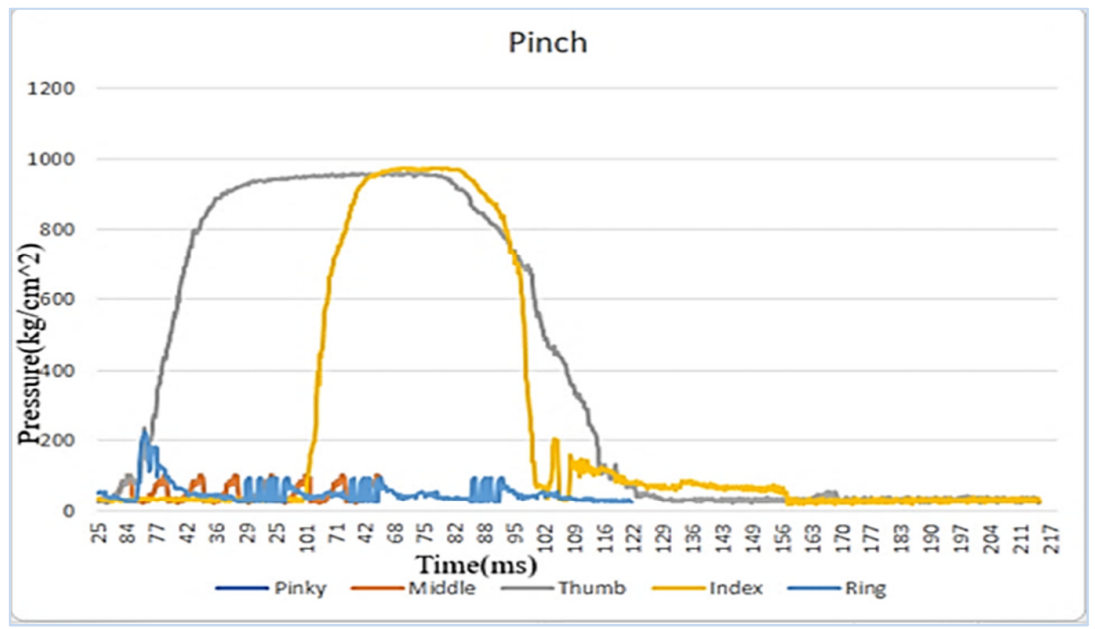

Fig. 19. Value of pressure sensor with pinch. 


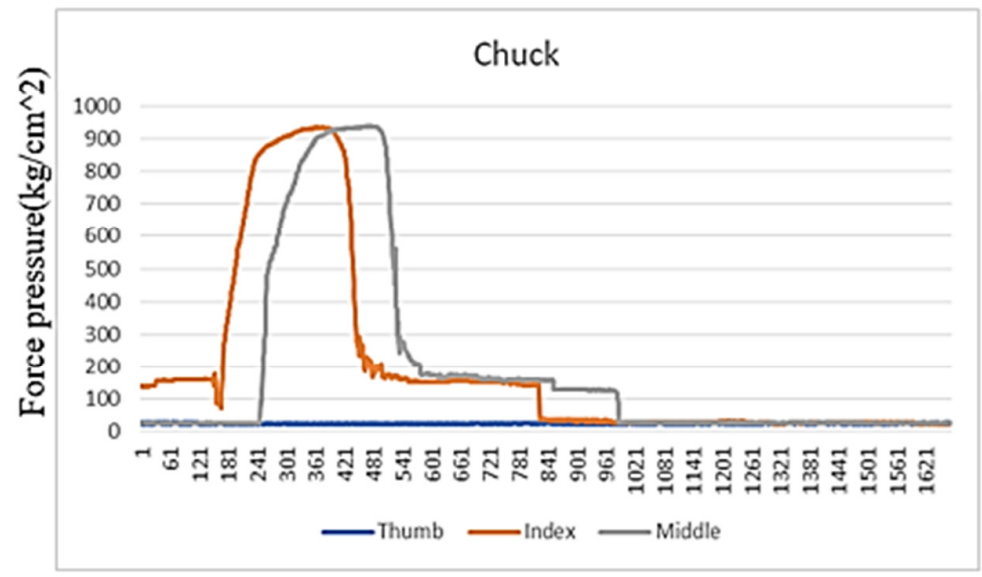

Time(ms)

Fig. 20.Value of pressure sensor with chuck.

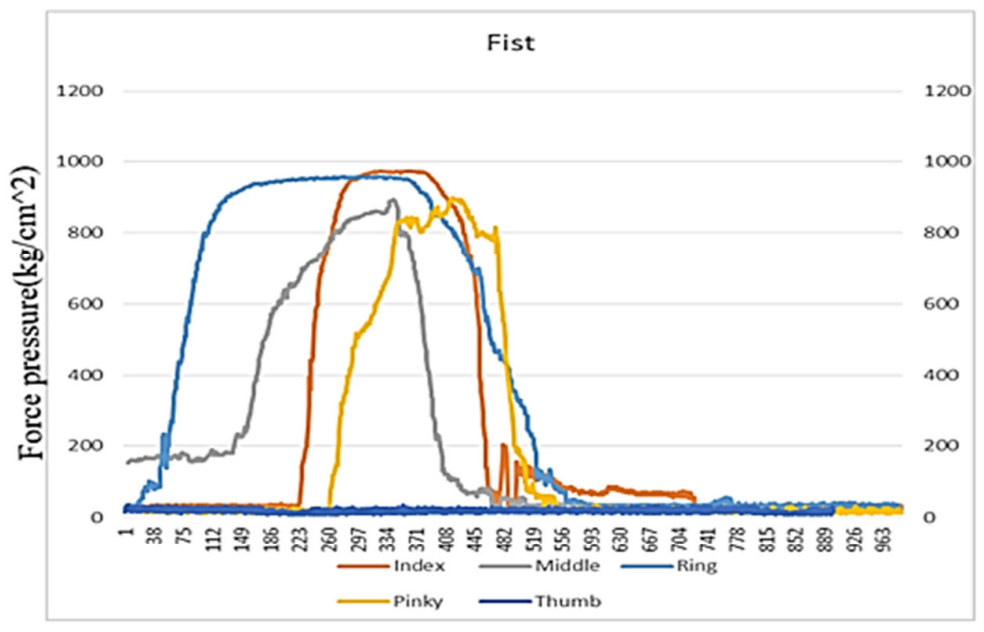

Time(ms)

Fig. 21. Value of Pressure Sensor with Fist.

\section{Conclusion}

The prosthetic hand presented in this work was factory-made via 3D printing strategies. The fingers unit was accomplished by Polou 6V DC motor through a worm gear equipped with worm wheel close to the finger. The five fingers, wrist, and the attachment have five independent degrees of freedom. Each finger is controlled by one motor while the thumb is controlled by 2 motors. The DC motor is mounted in palm. After collecting the signals for contracting the muscle for a period of one, two, and three seconds using EMG, the motions (pinch, fist, jack chuck). The designed hand has successfully accomplished the test of different gripping samples. The worm gear mechanism and the DC motors selection were the right choice for controlling the fingers rotational motion.

\section{References}

[1]S.micera, J.Carpaneto, S. Raspopovic," Control of hand prostheses using peripheral information" IEEE Reviews in Biomedical Engineering, vol. 3. No.1, pp.48-68, 2010.

[2] S.-y. Jung, S.-k. Kang and I. Moon, "Design of Biomimetic Hand Prosthesis with Tendon driven Five Fingers," in 2nd Biennial IEEE/RAS-EMBS International Conference Biomedical Robotics and Biomechatronics, Scottsdale Arizona USA, 2008.

[3]H.-M. Schmidt and U. Lanz, SurgicanAnatomy of the Hand, Thieme, 2003. 
[4]C. Pylatiuk, S. Mounier, A. Kargov, S. Schulz, G. Bretthauer," Progress in the development of a multifunctional hand prosthesis" , Proceedings of the 26th Annual international conference of the IEEE EMBS san francisco, CA, USA, September 1-5, 2004.

[5] I. Y. T. Maeno, "Five-fingered robot hand using ultrasonic motors and elastic elements", Proceedings of the 2005 IEEE International conference on robotics and automation barcelona, spain, april (2005).

[6]E. Tuomas. Wiste, A. S. Dalley, J. Thomas. Withrow and M. Goldfarb, "Design of a multifunctional anthropomorphic prosthetic hand with extrinsic actuation," in IEEE international conference on rehabilitation robotics, Japan, 2009.

[7]D. N. Rocha, C. de Moraes, et.al," Grip force analysis in a 3D hand prosthesis model", Brazilian congress of mechanical engineering, brazil, 2011.

[8]T. Joseph. MS. BS. Belter, L. Jacob . et.al, "Mechanical design and performance specifications of anthropomorphic prosthetic hands ", JRRD, Vol.50, No.5, pp. 599-618, 2013.

[9] G.K .Jones, R. Stopforth, "Mechanical design and development of the touch hand II prosthetic hand" R\&D Journal of the South African institution of mechanical engineering, pp. 23-34, 2016.

[10] Abd Al-Sahib N. Kadhim, A. M. Muhammed, and H. S. Falah, "Design and manufacture a 3D printed artificial hand",American Journal of Engineering Research (AJER), no. 2, pp. 156-164, 2018.
[11] R. Ozawa, H. Kobayashi and K. Hashirii, "Analysis, Classification, and design of tendon-driven mechanisms", IEEE transactions on robotics, 2014 , vol. 30, no. 2 , pp. 369-400.

[12] Micheal King, Brienna Phillips, Marc Shively, Venkatch Raman, Aaron Fleishman, Sarah Ritter and Khanjan Mehta, "Optimization of Prosthetic Hand Manufacturing", Proceeding in IEEE 2015 Global Humanitarian Technology Conference, USA, 2015.pp.59-61.

[13] Collins English Dictionary - Complete and Unabridged, 12th Edition 2014 , HarperCollins Publishers 1991, 1994, 1998, 2000, 2003, 2006, 2007, 2009, 2011, 2014/ https://www.thefreedictionary.com/worm+ge ar.

[14] G.K. Jones and R. Stopforth," Mechatronic Design And Optimisation of a low-cost prosthetic hand ", MSc thesis submitted University of KwaZulu-Natal,2015.

[15] S. M. Roberts,'Investigation into the control of an upper-limb myoelectric prosthesis", university of plymouth, 2002.

[16] R. M. Howard, "Investigation of Pattern Recognition System based On EMG Signals for optimal electrodes number and Positions" Boletin epidemiologico semanal, vol.10, no. 12, pp. 121-124, 2002. 


\title{
تطوير تصميم الطرف الاصطناعي باستخدام علبة تروس لتكرار آلية اليد البشرية
}

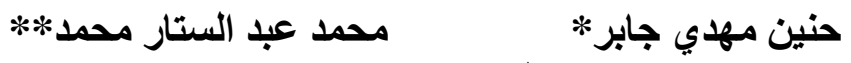

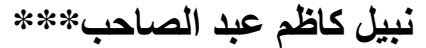

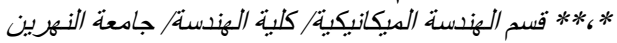

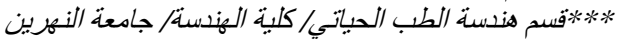

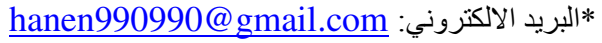

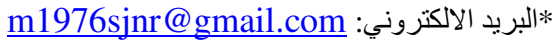 \\ البريد الالكتروني: البكني:
}

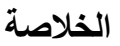

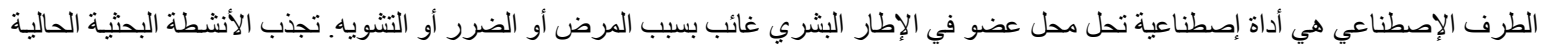

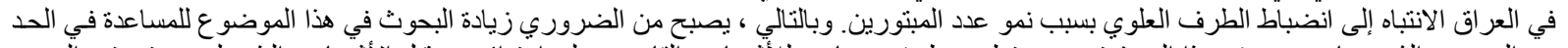

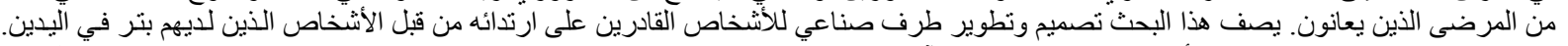

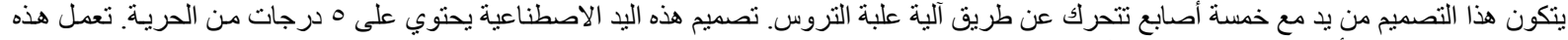

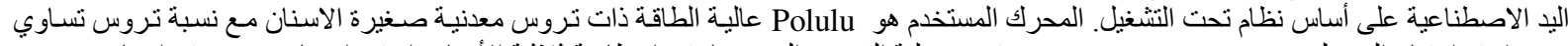

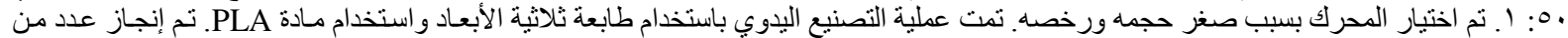

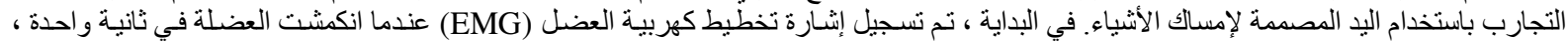
ثانيتين ، ثلاث ثوان. كانت اليد الاصطناعية قادرة على إنتاج مجمو عة من الإيماءات و الإمساك بالأثنياء. 